\title{
Portföy Analizinde Beklenen Getiri Sorunu: Markov Getiriler ve Basit Getirilerin Karşılaştırılması
}

\begin{abstract}
Salih ÇAM1
Özet

Ortalama varyans modeline göre optimal portföyler oluşturulurken yatırım araçlarının geçmiş değerlerinden yararlanarak hesaplanan birinci moment (getiri) ve ikinci moment (varyans) değerleri kullanılmaktadır. Amaç, belli bir getiri değerine bağlı olarak minimum riskli portföyler olușturmak veya belli bir risk değerine bağlı olarak maksimum getiri elde etmektir. Fakat kullanılan risk ve beklenen getiri ölçütüne göre portföydeki hisse senetleri çeşitliliği ve hisse senedi ağırlıkları farklllık göstermektedir. Dolayıslyla doğru risk ve getiri ölçüsü kullanmak daha etkin portföyler oluşturmak için önemlidir. Bu çalışmada literatürde yaygın olarak kullanılan klasik getiri ölçüsü (geçmiş getirilerin beklenen değeri "Basit getiri") ile Markov zincirleri modellerinden elde edilen getiriler karșılaștırılmış ve bu getirilerin portföy oluşturma üzerindeki etkileri incelenmiștir. Markov getirili modellerin basit getirili modellerden daha etkin portföyler olușturduğu sonucuna ulaşılmıştır.
\end{abstract}

Anahtar kelimeler: Markov zincirleri modelleri, ortalama-varyans modeli, hisse senedi getirileri,BIST30 Jel Kodu: G10, G11, G17

\section{Expected Returns Issue in Portfolio Analysis: A Comparison of Markov Chains' Returns and Simple Returns \\ Abstract}

In mean-variance model, the first moment (mean) and the second moment (variance) of variables are used in the phase of portfolio selection. The aim is to select portfolio that has minimum variance depending on given expected return or to select portfolio that has maximum return depending on given risk. But, according to measurement of expected returns and variance used in portfolio, the weights of stocks and the performance of portfolio would differ from one measurement to another. So, using the correct measurement of expected return and variance is crucial for construction of efficient portfolios. In this article, the expected returns obtained from Markov chain models are compared with expected returns obtained from historical data, and the effects of these returns are investigated on portfolio selection. As a result, portfolio with expected returns of Markov chain model construct more efficient portfolios.

Keywords: Markov chain models, mean-variancde model, retuns of stock XU030

Jel Codes: G10, G11, G17

\section{GíRiş}

Bir ekonomideki aktörler, bireysel yatırımcılar ve çeşitli kuruluşlar, tasarruf ettikleri fonları en verimli şekilde değerlendirerek fon büyüklüklerini artırmayı hedeflerler. $\mathrm{Bu}$ doğrultuda, uygun portföyler oluşturmayı amaçlarlar. Portföy oluştururken yatırımcı, yatırım riski ile karşılaşır. Yatırım riski en genel anlamıla, yatırımciların hem kazanma hem kaybetme yönünde gelecekte karşılaşabilecekleri belirsizlik düzeyi olarak tanımlanabilir (Head ve George, 1967). Burada belirsizlik ile risk birbiri ile karıștırılmamalıdır. Çünkü belirsizlik ve risk kavramları birbirinden farklıdır. Belirsizlik durumları sübjektif ihtimalleri kapsarken, risk objektif ihtimalleri kapsar. Bir hisse senedinin geçmiş verilerini kullanarak elde edilen risk ölçütü objektif bir risk ölçütüdür. Fakat aynı hisse senediyle ilgili gelecek beklentisi sübjektif bir ölçüttür ve

ATIF ÖNERISİ (APA): ÇAM, S. (2021). Portföy Analizinde Beklenen Getiri Sorunu: Markov Getiriler ve Basit Getirilerin Karşılaştırılması. İzmir İktisat Dergisi. 35(1). 81-95. Doi: 10.24988/ije.202136106

${ }^{1}$ Arş. Gör., Çukurova Üniversitesi, İ.İ.B.F., Sarıçam/ADANA, EMAIL: scam@cu.edu.tr ORCID: 0000-0002-3521-5728 
belirsizlik olarak adlandırılır (Aksoy ve Tanrıöver 2007, s.37). Hisse senetlerinin verimlilikleri araştırılırken kullanılan risk objektif risktir. Risk kendi içinde iki farklı şekilde tanımlanmaktadır. Portföyün riski ve portföy dışındaki risk. Başka bir ifade ile sistematik ve sistematik olmayan risk olarak da sınıflandırılabilir. Ekonominin genel yapısı, piyasalarda meydana gelen olumlu/olumsuz gelişmeler veya beklentiler, savaş ve doğal afet gibi durumlar ekonominin bütün bileşenlerini etkilemektedir. Böyle bir durumda az veya çok ama muhakkak, tüm hisse senetleri etkilenmektedir. Buna sistematik risk denilmektedir. Sistematik riskler hesaplanması mümkün olmayan veya modellenemeyen risklerdir. Portföy oluştururken yatırımcı bu riskleri göz önünde bulundurmalıdır.

Bilindiği üzere modern anlamda ilk portföy oluşturma fikri Markowitz (1952) tarafından ortaya atılmıștır. Markowitz portföy olușturma fikrini belli bir risk kabulü altında portföyün beklenen getirisini maksimum yapmak veya belli bir beklenen getiri kabulü altında portföy riskini minimum yapmak üzerine kurmuştur. Rasyonel bir yatırımcı yatırımından maksimum getiri elde etmek için sadece en yüksek getiri oranına sahip hisse senedine yatırım yapacaktır. Başka bir hisse senedi veya hisse senedi grubunun getirisi bu getirini üzerine çıkamadığı için maksimum getiri elde edecektir. Bu noktada, en yüksek getiriye sahip hisse senedinin doğru belirlenebilmesi çok önemlidir. Literatürde hisse senedinin beklenen getirisini hesaplama yöntemlerinin tamamı en doğru beklenen getiriyi hesaplamayı amaçlamaktadır. Markowitz (1991) yılında yayımladığı makalesinde konuyla ilgili şöyle demektedir; "Hangi hissenin en yüksek getiriye sahip olacağını bilseydik çeşitlendirmeye gerek kalmadan sadece o hisseye yatırım yaparak getirimizi maksimum yapardı. Fakat hiçbirimiz hisse senedinin yatırım dönemi için dağılım fonksiyonunu bilmiyoruz. Dolayısıyla yatırım yaparken birtakım risklerle karşı karşıya kalırız ve çeşitlendirme yoluyla maruz kaldığımız riski dağıtmaya çalışırız."
Portföy olușturulurken birçok risk ölçütü ve birçok beklenen getiri ölçütü kullanılmaktadır. En yaygın kullanılan beklenen getiri hesaplaması hisse senedinin tarihsel verilerinden yola çıkarak basit ortalama hesaplamaktır. Bu hesaplama yapılırken örtük olarak hisse senedinin yatırım dönemindeki davranışı, örneklem dönemindeki davranışlarıyla aynı olacağı varsayımı yapılmaktadır. Fakat bilindiği gibi finansal piyasaların davranışları dönemden döneme önemli farklılıklar göstermektedir. $\mathrm{Bu}$ farklılıkların temelinde siyasi konjonktür, ekonomik konjonktür, yatırımcı beklentileri, sektörel gelişmeler, döviz kuru, alternatif yatırım araçları, faiz oranları, şirketlerin politikaları gibi birçok parametre yer almaktadır [bkz. Ibrahim,1999; Nisa ve Nishat, 2011; Singh, 2010; Kwon, 1999; Barakat vd., 2016; Rjoub vd., 2017]. Bunların tamamı yatırım riski olarak karşımıza çıkar ve portföy performansinı olumlu/olumsuz etkiler. Yukarıda sıralanan faktörler bir tarafa, teknik olarak portföy oluşturma aşamasında beklenen getirinin ve riskin en az hata ile tahmin edilmesi, portföy performansı açısından son derece önemlidir. Bu çalışmada literatürde az kullanılan bir beklenen getiri hesaplama yöntemi (Markov zincirleri modelleri) ile çok daha yaygın kullanılan ortalama ölçüsü arasında bir karşılaştırma yapılmıştır.

Analize geçmeden önce yatırımcının yatırım döneminde karşılaşabileceği risk çeşitlerinin ve beklenen getiri hesaplama yöntemlerine değinilmiştir. Öncelikle risk çeşitleri aşağıdaki şekilde özetlenebilir;

Satın Alma Gücü Riski: Satın alma gücü riski reel gelirin düşmesi durumunda ortaya çlkar. Yatırımcının belli bir portföye yatırım yaptığ varsayımıyla; Bir dönem sonra yatırımlarının karşıllğı olarak elde ettiği gelir fiyatlar genel seviyesinin yükselme hızından daha az ise yatırımcının reel geliri azalmış demektir. Reel gelirin artması ancak nominal gelir artışının enflasyon oranından daha yüksek olduğu durumlarda mümkündür [bkz. Mishkin, 2007; Aksoy ve Tanrı̈ver, 2007]. 
Faiz Oranı Riski: Yatırımc hisse senedine yatırım yaptığı her bir lira için faiz kazancından vazgeçmektedir. Dolayısıyla faiz oranlarının yükselmesi ile yatırım getirisinin faiz oranın altında kalma olasılığı ortaya çıkmaktadır. Bilindiği gibi tahvil fiyatları ile faiz oranları arasında da ters yönlü bir ilişki vardır. Faiz oranlarının artmasıyla birlikte tahvilin piyasa değeri düşecektir (Mishkin, 2007, ss.121). Dolasıyla tahvil özelinde tüm kupon ödemeleri ve faiz ödemeleri tahvilin değer (servet) kaybını karşılamazsa yatırımcı negatif kar elde edecektir.

Pazar Riski: Pazar riski yatırım aracının işlem fiyatındaki değişimlerden kaynaklı risklerdir. Pazar riski tahvil/bono gibi yatırım araçları için de geçerli olmasına rağmen hisse senetleri bu riski daha çok taşır. Satın alınan bir hisse senedinin fiyatı piyasa koşullarında düşebilir ve yatırımcı servet kaybıyla karşı karşıya kalabilir. Böyle bir durumda hisse senedinin verimliliği, dolayısıyla portföyün verimliliği düşecektir. [bkz. Aksoy ve Tanrı̈ver, 2007; Doğukanlı ve Borak, 2018 Klaasen ve Eeghen, 2009]

Politik Risk ve Kur Riski: Gelişmekte olan ülke ekonomilerinde finansal piyasalar politik ve kur risklerine oldukça duyarlıdır. Döviz, yabancı bir yatırım aracı olduğundan dövizdeki bir yükseliş (yerel paranın değer kaybetmesi) beklentisi döviz talebini, dolayısıyla tahvil/bono veya hisse senedinin fiyatını düşürecektir. Bu durum portföyün verimliliğini azaltacaktır. [Dooley ve Isard, 1980; Bailey ve Chung, 1995; Mishkin, 2007]

Yukarıda kısaca açıklanan riskler sistematik risk grubundadır ve yatırımcının kontrolü dişında gerçekleşir. Sistematik olmayan riskler ise genel olarak üç grupta incelenebilir.

Finansal Risk: Yatırımcı bir hisse senedi satın aldığında ilgili şirketin hem karına hem de zararına ortak olmaktadır. Yatırımcının yatırım yaptığı şirket iflas edebilir. $\mathrm{Bu}$ durumda yatırımcı da parasını kaybedecektir. $\mathrm{Bu}$ tür risklere finansal riskler denir. [bkz. Mwaurah vd., 2017; Williams, 2011.]
Endüstri Riski: Konjonktür olarak bazı sektörler genişlerken bazı sektörler daralabilir. $\mathrm{Bu}$ daralmalar spesifik bir sektörden veya toplumsal tercihlerin değişmesinden kaynaklanabilir. Örneğin bir ülkede maden şirketlerine ait yasal bir düzenleme şirketleri ciddi ekonomik sıkıntıya sokabilir ve bu sektörde işlem gören şirketlerin hisse senetleri değer kaybına uğrayabilir. Sonuçta hisse senedinin, dolayısıyla portföyün verimliliği düşebilir.

Yönetim Riski: Yönetim riski yatırım yapılan şirketin yönetiminden kaynaklanan risklerdir. Yatırımcının yatırım yaptığı bir şirketin yanlış politikaları ve kararları yatırımcıyı da zarara uğratacaktır. Bu risk şirkete özel risktir ve literatürde idiosyncratic olarak adlandırılmaktadır. [bkz. Goyal ve Clara, 2003; Fu, 2009; Bali vd., 2005; Huang vd., 2010; Glovar ve Levine, 2017]

Bir yatırımda karşılaşılabilecek riskler yukarıda kısaca açıklanmıştır. Portföy seçiminde kullanılan risk ölçütü kadar beklenen getiri ölçütü de önemlidir. Doğru beklenen getiri hesaplamaları daha etkin portföy seçimleri anlamına gelirken, doğru yapılmayan beklenen getiri tahminleri portföy etkinliğini düşürecektir. Bu çalışmanın çıkış noktasını oluşturan konu da portföy seçimi yapilırken hangi beklenen getiri hesaplamasının kullanılması gerektiğidir.

Şüphesiz portföy seçiminde birçok beklenen getiri tahmin yöntemi kullanılmaktadır. Fakat burada literatürde en çok kullanılan, basit ortalama da dediğimiz ortalama hesaplama yöntemi ile daha doğru tahmin ürettiğini düşündüğümüz ve Markov zincirlerinin durağan durum olasılıklarından hesaplanan beklenen getiriler karşılaștırılmıștır.

Aşağıda basit ortalama ve CAPM model ile elde edilen getiriler kısaca tanıtılmış ve portföy analizinde kullanıldıklarında çıkabilecek sorunlara değinilmiştir.

Basit ortalama beklenen getiri: Burada hisse senedinin geçmiş değerlerinin ortalaması alınarak beklenen getiri hesaplanmaktadır. 
Basit anlamda bir ortalama hesabıdır ve literatürde en çok kullanılan beklenen getiri ölçüsüdür. Basit getiriler kullanıldığında örtük olarak iki varsayım yapılmaktadır. İlki, analize konu edilen hisse senetlerinin tarihsel olarak aynı veya benzer bir dağılıma sahip olacağı varsayılmaktadır. Fakat bir hisse senedinin tahmin dönemindeki (örneklem dönemi dışındaki dönem) dağılımının, örneklem dönemindeki dağılım ile aynı olacağını garanti eden hiçbir bulgu yoktur. $\mathrm{Bu}$, özellikle çok değişken bir yapıya sahip olan finansal veriler için oldukça iyimser bir varsayımdır. İkinci olarak, tarihsel verilerden basit getiri hesaplanırken bu verilerin ait olduğu hisse senedi getirilerinin normal dağılımdan geldiği varsayılmaktadır. Fakat literatürde birçok çalışma hisse senedi getirilerinin genel olarak kalın kuyruk dağılıma sahip olduğunu göstermektedir [bkz. Officer, 1972; Bea vd., 2020; Eom vd., 2019].

CAPM: Model ilk olarak Sharpe (1963) tarafından ortaya atılmıştır ve Lintner (1965) tarafından geliștirilmiştir. Model, genel olarak bir hisse senedinin riski ne kadar yüksek ise beklenen getirisinin de o denli yüksek olması gerektiği fikrine dayanmaktadır. CAPM modeli geniş bir uygulama alanı bulmasına rağmen gerisinde yatan varsayımların gerçekçi olmaması bu modele yapılan en büyük eleștiri olmuştur (Aksoy ve Tanrıöver, 2007, ss. 646). Modeli aşağıdaki şekilde ifade edebiliriz;

$E\left(r_{i}\right)=R_{f}+\beta_{i}\left[E\left(r_{m}\right)-R_{f}\right]$,

Burada $E\left(r_{i}\right)$ i. hisse senedinin beklenen getirisi, $R_{f}$ risksiz faiz oranı, $\beta_{i}$ i. hisse senedinin beta katsayısı, $E\left(r_{m}\right)$ piyasa ortalama getirisidir. Yukarıda sıralanan iki yöntem en çok kullanılan beklenen getiri hesaplama yöntemlerinden ikisidir. Basit beklenen getiri gibi CAPM model de getirilerin normalliği üzerine inşa edilmiştir. Sonuçta CAPM model tahmininde sıklıkla en küçük kareler (EKK) regresyon modeli kullanılmaktadır. EKK yönteminde tüm katsayı sınama testleri ve güven aralıkları, hata teriminin normal dağıldığını varsaymaktadır (Gujarati, 2012).

\section{YÖNTEM}

Modern portföy teorisi Markowitz (1952) ile birlikte başladığı varsayılmaktadır. Markowitz ortalama-varyans modelinde verimliliğin ölçüsü olarak ortalama beklenen getiriyi, riskin ölçüsü olarak da varyans-kovaryans matrisini kullanmıștır [bkz. Buser, 1977; Demirtaş ve Güngör, 2004, Lui vd., 2003]. Markowitz'in çalışmasından sonra ortalama-varyans modeli hem eleştiri almıştır hem de portföy seçiminde en önemli araç olarak kullanılmaya başlanmıştır. Bunun yanında Markov zincirleri modelleri gibi modeller de portföy analizinde kullanım alanı bulmuştur [Bkz: Kadir vd., 2014; Cyert ve Thompson, 1968; McQueen ve Thorley, 1991; Doubleday ve Esunge, 2011]. Bu çalışmada da Markov zincirleri modelleri BIST30 endeksindeki hisse senetlerinden oluşturulacak portföylerde kullanılmıștır ve oluşturulan portföyler, basit beklenen getirili portföylerle karşılaştırılmıştır.

Analizde BIST30 endeksindeki 28 hisse senedinin 01/012018 ile 31/12/2019 tarihleri arasındaki günlük kapanış fiyatları verisi kullanılmıştır. Veriler Borsa İstanbul A.Ş veri tabanından alınmıştır. Kullanılan her bir hisse senedinin günlük getirisi $\left(\ln \left(p_{t+1}\right)-\ln \left(p_{t}\right)\right)$ olarak hesaplandıktan ( $\mathrm{p}$ burada hisse senedi günlük kapanış fiyatıdır) sonra sistem pozitif getiri, sıfır (nötr) getiri ve negatif getiri olmak üzere üç durumlu Markov süreci olarak modellenmiştir. Durumlar arası geçiş olasılıkları ve uzun dönem denge (durağan) olasılıkları, geçiş olasılıkları matrisinden elde edilmiştir. Hesaplanan geçiş olasılıkları ve durağan denge olasılıkları yardımı ile her bir hisse senedinin beklenen getiri oranları hesaplanmıştır. Sonuç olarak en yüksek getiriye sahip portföyler oluşturulmuş ve bu portföyler basit getirili portföylerle karşılaştırılmıştır.

\subsection{Markov Zincirleri Modelleri}

Markov zincirleri modelleri birinci dereceden ve aşağıdaki şekilde modellenmiştir.

$S_{t} \quad\{1,2,3, \ldots, N\}$ tamsayı değerleri alan rassal dağılan bir değişken olsun. $S_{t}^{\prime}$ nin şimdiki 
değerinin sadece $S_{t-1}$ dönemine bağlı olduğunu varsayalım. Yani;

$$
P\left\{s_{t}=j / s_{t-1}=i, s_{t-2}=k, \ldots . .\right\}=P\left\{s_{t}=j / s_{t-1}=i\right\}=P_{i j}
$$

Böyle bir süreç $\left\{P_{i j}\right\}_{i, j=1,2,3, \ldots, N}$ olasılık matrisli N durumlu Markov süreci olarak tanımlanır. $P_{i j}$, durum i'den durum j'ye geçiş olasıllı̆ını ifade etmektedir. Durum i'den diğer tüm durumlara geçme olasilıkları toplamı $p_{i 1}+p_{i 2}+\ldots \ldots .+p_{i N}=1$ 'dir. Bütün geçiş olasılıklarını (NxN) boyutlu P geçiş olasılıkları matrisinde toplamak uygundur.

$P=\left[\begin{array}{cccc}p_{11} & p_{12} & \ldots & p_{1 N} \\ p_{21} & p_{22} & \ldots & p_{2 N} \\ \ldots & \ldots & \ldots & \ldots \\ p_{N 1} & p_{N 2} & \ldots & p_{N N}\end{array}\right]_{N X N}$

P matrisinde kolon j ve satır i $P_{i j}$ geçiş olasılığını göstermektedir (Hamilton, 1994).

Geçiş olasılıkları matrisi yardımı ile denge durumu olasilıkları da denilen durağan durum geçiş olasılıkları hesaplanmaktadır. Geçiş olasılıkları matrisi kısa dönem (sadece bir sonraki dönem) olasılıkları içerirken, durağan durum olasılıkları sistemin zamandan bağımsız her bir durumun aldığı olasilıklarını ifade etmektedir. Beklenen getirilerin durağan olasılıklardan hesaplanmasının nedeni, çalışmanın başında belirtilen hisse senedi dağılımlarının zaman içinde değişmesi problemine çözüm üretmektir. Çünkü durağan durum olasılıkları bir sonraki dönem için sistemin olasılıklarını değil, bir bütün olarak her durumunun ortalama alacağı olasılık değerlerini vermektedir. Başka bir ifade ile durağan olasılıklar hisse senetleri getirilerinin zamandan bağımsız ortalama durum olasılıklarını hesaplamaktadır. Böylelikle hisse senedi getiri dağılımlarının zaman içinde değişme durumuna karşı dirençli bir beklenen getiri elde edilmektedir.

$\mathrm{N}$ durumlu Markov zincirleri için durağan durum olasılıkları (Nx1) boyutundaki $\pi$ vektörü olarak gösterilmektedir. $\pi$ vektörü;
$P . \pi=\pi \quad$ koșulunu sağlamaktadır. $\pi$ özdeğer vektörünün elemanları toplamı 1 olduğu için $\pi$ vektörünün normalleştirilmiş olduğu söylenebilir. Ya da $\lim _{m \rightarrow \infty} P^{m}=\pi .1^{\prime} \quad$ olarak gösterilebilir (Hamilton,1994, s. 681). Başka bir ifade ile $\mathrm{n}$ yeterince büyük olduğu düşünülürse $P^{n+1}=P^{n}$

eşitliğinde $\mathrm{P} \quad(\mathrm{NxN})$ matrisinin köşegen elemanları durağan durum geçiş olasılıklarını verecektir.

\subsection{Ortalama-Varyans Modeli}

Markov zincirleri modelleri yardımıyla elde edilen getiriler hesaplandıktan sonra basit ortalama getiriler ile Markov getirilerinin portföy optimizasyonu üzerindeki etkisini incelemek amaciyla ortalama-varyans modeli kullanılmıştır. Optimal portföyler elde edilirken belli bir portföy riskine bağlı olarak getiriyi maksimum yapan optimal portföyler oluşturulmuştur. İlk modellerde portföy riski ve toplam ağırlıkların bire eşit olması dışında modellere kısıt eklenmemiştir. İkinci modellerde ise portföy çeşitlendirmesi amacıyla her bir hissenin portföy içindeki ağırlığının maksimum 0.35 olması kısıtı eklenmiştir. Hiçbir modelde açığa satışa izin verilmemiştir. Yani tüm hisselerin ağırlıkları büyük eşit sıfırdır. Optimize edilen ortalama varyans modeli aşağıdaki şekildedir. Birinci model için

$$
\begin{gathered}
\text { maksimum } Z=w^{l} \mu \\
\text { Kısitlar: } w^{\imath} \sum w=\sigma_{0}^{2} \\
w^{l} l=1
\end{gathered}
$$

Burada $\mathrm{w}$ hisse senetlerinin portföy içindeki ağırlık vektörü, $\mu$ hisse senetlerinin ortalama getiri vektörü, $\sum$. hisse senetlerinin varyans vektörü ve $\sigma_{0}^{2}$ ise keyfi belirlenmiş portföy riski oranıdır (Pabozzi vd., 2007, ss. 25). Portföy riski için bir alt limit belirlendikten sonra risk, her defasında $\% 10$ artırılarak yeni portföyler oluşturulmuştur. İkinci modellerde ise yukarıdaki doğrusal programlama problemine

$$
w^{2} \leq 0.35
$$


kısıtı eklenmiştir. Böylelikle portföy çeşitlendirmesi sağlanmıştır. Buradaki amaç her iki getiri hesaplama yönteminin çeşitlenmiş portföy üzerindeki etkisini belirlemektir.

\section{ANALİZ VE BULGULAR}

Analizde BIST30 endeksinde işlem gören 28 hisse senedi kullanılmıştır. Bu hisse senetleri Tablo 1'de verilmiştir. Her bir hisse senedine ait geçiş olasılıkları matrisi ve uzun dönem denge (durağan) olasılıkları hesaplanmıștır. Bütün hisse senetleri için negatif getirilerin beklenen değeri ile pozitif getirilerin beklenen değerleri hesaplandıktan sonra her bir hisse senedinin verimliliği Markov zincirleri yardımı ile elde edilmiştir.
Tablo 1: Hisse Senetleri ve Kisaltmaları

\begin{tabular}{cc|cc}
\hline Hisse Senedi & Kisaltma & Hisse Senedi & Kisaltma \\
\hline AKBNK & H1 & PGSUS & H15 \\
ARCLK & H2 & PETKM & H16 \\
ASELS & H3 & SAHOL & H17 \\
BIMAS & H4 & SODA & H18 \\
DOHOL & H5 & SISE & H19 \\
EKGYO & H6 & TAVHL & H20 \\
FROTO & H7 & TKFEN & H21 \\
GARAN & H8 & TOASO & H22 \\
EREGL & H9 & TUPRS & H23 \\
ISCTR & H10 & THYAO & H24 \\
KRDM & H11 & TTKOM & H25 \\
KCHOL & H12 & TCELL & H26 \\
KOZAL & H13 & VAKBN & H27 \\
KOZAA & H14 & YKBNK & H28 \\
\hline
\end{tabular}

Tablo 2: Durağan Durum Olasılıkları

\begin{tabular}{|c|c|c|c|c|c|c|c|}
\hline Hisse Kodu & Artma Ols. & Aynı Kalma Ols. & Azalma Ols. & Hisse Kodu & Artma Ols. & Aynı Kalma Ols. & Azalma Ols. \\
\hline AKBNK & 0.466 & 0.033 & 0.502 & PGSUS & 0.522 & 0.006 & 0.472 \\
\hline ARCLK & 0.471 & 0.012 & 0.516 & PETKM & 0.448 & 0.054 & 0.498 \\
\hline ASELS & 0.455 & 0.062 & 0.484 & SAHOL & 0.506 & 0.032 & 0.462 \\
\hline BIMAS & 0.504 & 0.016 & 0.480 & SODA & 0.490 & 0.034 & 0.476 \\
\hline DOHOL & 0.418 & 0.179 & 0.414 & SISE & 0.494 & 0.034 & 0.472 \\
\hline EKGYO & 0.402 & 0.160 & 0.449 & TAVHL & 0.532 & 0.008 & 0.460 \\
\hline FROTO & 0.523 & 0.020 & 0.458 & TKFEN & 0.498 & 0.008 & 0.494 \\
\hline GARAN & 0.478 & 0.010 & 0.512 & TOASO & 0.487 & 0.018 & 0.493 \\
\hline EREGL & 0.454 & 0.034 & 0.458 & TUPRS & 0.494 & 0.020 & 0.486 \\
\hline ISCTR & 0.486 & 0.038 & 0.476 & THYAO & 0.470 & 0.010 & 0.520 \\
\hline KRDM & 0.426 & 0.072 & 0.475 & ТTКОМ & 0.496 & 0.040 & 0.464 \\
\hline KCHOL & 0.472 & 0.016 & 0.512 & TCELL & 0.502 & 0.024 & 0.474 \\
\hline KOZAL & 0.514 & 0.014 & 0.472 & VAKBN & 0.486 & 0.036 & 0.478 \\
\hline KOZAA & 0.482 & 0.020 & 0.498 & YKBNK & 0.421 & 0.100 & 0.454 \\
\hline
\end{tabular}

Tablo 2 hisse senetlerine ait uzun dönem denge olasılıklarını göstermektedir. Örneğin tabloya göre AKBNK hissesi \%46,56 olasılıkla artarken, $\% 0,324$ olasılıkla aynı kalmakta ve \%50,2 olasılıkla azalmaktadır. Bu olasılıklar durağan durum denge olasılıkları olduğu için zaman boyutundan arınmıştır.

TAVHL, \%53,21 artış olasılığı ile en yüksek orana sahip hisse senedidir. Bu hisse senedini FROTO, \%52,27 artış oranı ile takip etmektedir. En çok düşüş olasılığı ise \%52,01 
ile THYAO hisse senedine aittir. Hisse değerinin aynı kalma olasılıkları incelendiğinde ise DOHOL \%17,87 ile en yüksek orana sahiptir. Tablodan da anlaşlacağı gibi hisse senetleri zaman içinde genellikle artma veya azalma eğilimindedir. Hisse senedi getiri oranlarının aynı kalma olasılıkları diğer iki durum olasılıklarına göre görece daha düşüktür.

Tablo 3 hisse senetlerine ait pozitif getirilerin beklenen değeri ile negatif getirilerin beklenen değerlerini göstermektedir. Bu getiri oranları basit ortalama hesabı ile hesaplanmıștır ve bir adım sonra Markov zincirleri modelleri hisse senedi verimliliklerinin hesaplanması için kullanılacaktır. Fakat öncesinde Tablo 3 incelendiğinde bütün hisse senetleri getiri ortalamalarının $+\% 0,194$ ile $-\% 0,184$ arasında değiștiği görülmektedir. Değișim aralığına bakıldığında KOZAA, DOHOL, KRDM ve PGSUS hisseleri değişim aralıkları en yüksek hisse senetleri olarak görülmektedir. Bu oranlar yukarıda sıralanan hisse senetleri riskinin yüksek olduğuna işarettir. Başka bir ifade ile ilgili hisse senetlerinin oynaklık (volatilite) değerleri oldukça yüksektir.

BIMAS, KCHOL ve SODA hisse senetleri ise değişim aralıkları en düşük hisselerdir. Benzer bir yorum, bu hisse senetlerinin düşük riskli oldukları şeklinde yapılabilir.

Tablo 3: Pozitif/Negatif Ortalama ve Değişim Aralığ 1

\begin{tabular}{|c|c|c|c|c|c|c|c|}
\hline Hisse & $\begin{array}{c}\text { Pozitif } \\
\text { Ort. } \\
\text { (\%) }\end{array}$ & $\begin{array}{c}\text { Negatif } \\
\text { Ort. } \\
\text { (\%) }\end{array}$ & & Hisse & $\begin{array}{c}\text { Pozitif } \\
\text { Ort. } \\
(\%)\end{array}$ & $\begin{array}{c}\text { Negatif } \\
\text { Ort. } \\
(\%)\end{array}$ & $\begin{array}{c}\text { Değişim } \\
\text { Aralığı }\end{array}$ \\
\hline AKBNK & 0.0202 & -0.019 & 88 & PGSUS & 0.0231 & -0.022 & 0.0449 \\
\hline ARCLK & 0.0174 & -0.016 & 0.0332 & PETKM & 0.0173 & -0.017 & 0.0342 \\
\hline ASELS & 0 . & -0.018 & & SAHOL & 52 & -0.018 & 322 \\
\hline BI & & & & SODA & & & \\
\hline DOHOL & 0.0244 & -0.021 & & SISE & 78 & -0.018 & 0.0357 \\
\hline EKGYO & 0.0183 & -0.019 & 0.0371 & TAVHL & 0.0183 & -0.020 & 0.0378 \\
\hline FROTO & 0.0 & -0.0 & 38 & TKFEN & & -0 & 393 \\
\hline GARAN & & & & 0 & & & \\
\hline EREGL & 0.0182 & -0.018 & 0 & TUPRS & 0.0 & -0.016 & 26 \\
\hline ISCTR & 0.0189 & -0.020 & 0 . & THYAO & 0.0216 & -0.020 & 0416 \\
\hline KRDM & 0.0235 & -0.022 & 0.04 & TTKOM & 0.0196 & -0.020 & 0.0399 \\
\hline KCHOL & 0.0153 & -0.014 & & TCELL & 0.0158 & -0.017 & 0.0324 \\
\hline KOZAL & 0.0218 & -0.022 & 0.0429 & VAKBN & 0.0199 & -0.021 & 0.0409 \\
\hline KOZAA & 0.0260 & -0.023 & 0.0494 & YKBNK & 0.0199 & -0.019 & 0.0388 \\
\hline
\end{tabular}

Bunun yanı sıra genel olarak hisse senetlerinin pozitif getiri ortalamaları negatif getiri ortalamalarından daha yüksek hesaplanmıştır. Tablo 4 hisse senetleri için 1000 TL yatırım karşıllı̆ında pozitif getiri beklentisi, negatif getiri beklentisi, hisse senedi verimliliği ve yatırım sonucu elde edilecek toplam fon miktarlarını göstermektedir. Burada $1000 \mathrm{TL}$ keyfi olarak seçilmiş bir miktardır. Hisse senedi verimliliği, başka bir ifadeyle Markov zinciri getirileri hesaplanırken; öncelikle pozitif getiri oranları ve pozitif getiri durağan durum olasılıkları çarpılıp ortalama pozitif beklenen getiri hesaplanmıştır. Bu işlem negatif getiriler için de tekrarlandıktan sonra pozitif beklenen getiri, negatif beklenen getiri ve nötr beklenen getiriler bir arada kullanılarak hisse senedi Markov beklenen getirisi hesaplanmıştır.

Tablo 4: Pozitif Getiri, Negatif Getiri ve Yatırım Getirileri

\begin{tabular}{ccccc}
\hline Hisse & $\begin{array}{c}\text { 1000 TL'deki } \\
\text { artış }\end{array}$ & $\begin{array}{c}\text { TL'deki } \\
\text { azalıs }\end{array}$ & $\begin{array}{c}\text { Hisse } \\
\text { Verimliliği }\end{array}$ & $\begin{array}{c}\text { Beklenen } \\
\text { Getiri \% }\end{array}$ \\
\hline AKBNK & 1020.1980 & 981.4000 & 1000.0662 & 0.0066 \\
ARCLK & 1017.3559 & 984.1700 & 998.9820 & -0.1017 \\
ASELS & 1017.1820 & 982.3000 & 998.7253 & -0.1274 \\
BIMAS & 1012.9940 & 987.3330 & 1000.4704 & 0.0470 \\
DOHOL & 1024.4300 & 979.3920 & 1013.2126 & 1.3212 \\
EKGYO & 1018.2605 & 981.1870 & 1010.2622 & 1.0262 \\
FROTO & 1016.3240 & 982.5420 & 1001.6176 & 0.1617 \\
GARAN & 1020.6320 & 981.0700 & 1000.1671 & 0.0167 \\
EREGL & 1018.2072 & 982.4780 & 946.3058 & -5.3694 \\
ISCTR & 1018.8900 & 980.5400 & 999.9189 & -0.0086 \\
KRDM & 1023.5320 & 978.4600 & 972.9194 & -2.7080 \\
KCHOL & 1015.2960 & 986.3540 & 1000.6327 & 0.0633 \\
KOZAL & 1021.8070 & 978.8830 & 1001.9043 & 0.1904 \\
KOZAA & 1026.0200 & 976.6600 & 1000.1108 & 0.0118 \\
PGSUS & 1023.0890 & 978.1820 & 1001.7588 & 0.1758 \\
PETKM & 1017.2900 & 983.1200 & 999.8468 & -0.0153 \\
SAHOL & 1015.2200 & 982.9740 & 999.8384 & -0.0161 \\
SODA & 1015.3770 & 985.9450 & 1000.4169 & 0.0416 \\
SISE & 1017.7960 & 982.0550 & 1001.0223 & 0.1022 \\
TAVHL & 1018.3019 & 980.5040 & 1000.7739 & 0.0773 \\
TKFEN & 1020.0600 & 980.7500 & 1000.4806 & 0.0480 \\
TOASO & 1017.5250 & 982.3390 & 998.4327 & -0.1562 \\
TUPRS & 1016.7240 & 984.1440 & 1000.5561 & 0.0551 \\
THYAO & 1021.5760 & 980.0140 & 999.7438 & -0.0256 \\
TTKOM & 1019.6040 & 979.7400 & 1000.2508 & 0.0250 \\
TCELL & 1015.7635 & 983.3289 & 1000.0130 & 0.0013 \\
VAKBN & 1019.8820 & 978.9500 & 998.6738 & -0.1326 \\
YKBNK & 1019.8702 & 981.0610 & 975.0588 & -2.4941 \\
\hline Not: Tablo2 ve Tablo3 yardımiyla hesaplanmistır. & \\
& & & & \\
\hline
\end{tabular}

Hisse senetleri için hisse verimliliği; 


\section{S. ÇAM}

Verimlilik $=$

[Artma olasılı $\breve{g} l x\left(1000 T L^{\prime}\right.$ deki artıș)

+ Aynı kalma olasılığ

+ Azalma olasılığıx(1000 TL'deki azalma)]

olarak hesaplanmıştır. Örneğin YKBNK hissesi için verimlilik aşağıdaki şekilde elde edilmiştir.

$A K B N K=0.467 \times 1020.1980+0.032 \times 1000+0.502 \times 981.400$

Yatırım sonucu 1000 TL'deki artıș ve azalıșlar ise (pozitif/negatif getiri ortalaması)x(1000) olarak elde edilmiştir. Getiri oranları incelendiğinde en yüksek getiri \%1.3212 oraniyla DOHOL hisse senedine aittir. İncelediğimiz dönem için en fazla kayıp ise EREGL ile KRDM hisselerinde görülmüştür.

Tablo 5:Markov Beklenen Getirileri ve Ortalama Getiriler

\begin{tabular}{|c|c|c|c|}
\hline Hisse & $\begin{array}{c}\text { Markov Beklenen } \\
\text { Getiri \% }\end{array}$ & $\begin{array}{c}\text { Ortalama } \\
\text { Getiri } \%\end{array}$ & $\begin{array}{c}\text { Hisse } \\
\text { Varyansı }\end{array}$ \\
\hline AKBNK & 0.00663 & 0.00021 & 0.00063 \\
\hline ARCLK & -0.10179 & 0.00066 & 0.00048 \\
\hline ASELS & -0.12747 & -0.08132 & 0.00052 \\
\hline BIMAS & 0.04700 & 0.04846 & 0.00028 \\
\hline DOHOL & 1.32121 & 0.16800 & 0.00079 \\
\hline EKGYO & 1.02627 & -0.10935 & 0.00045 \\
\hline FROTO & 0.16177 & 0.05804 & 0.00051 \\
\hline GARAN & 0.01672 & 0.01614 & 0.00071 \\
\hline EREGL & -5.36944 & 0.02714 & 0.00051 \\
\hline ISCTR & -0.00816 & -0.00824 & 0.00060 \\
\hline KRDM & -2.70810 & -0.01487 & 0.00075 \\
\hline KCHOL & 0.06343 & 0.02827 & 0.00034 \\
\hline KOZAL & 0.19054 & 0.13238 & 0.00074 \\
\hline KOZAA & 0.01181 & 0.08861 & 0.00101 \\
\hline PGSUS & 0.17588 & 0.18771 & 0.00084 \\
\hline PETKM & -0.01532 & -0.06386 & 0.00051 \\
\hline SAHOL & -0.01616 & -0.01704 & 0.00042 \\
\hline SODA & 0.04167 & 0.08097 & 0.00037 \\
\hline SISE & 0.10224 & 0.03614 & 0.00048 \\
\hline TAVHL & 0.07739 & 0.07828 & 0.00061 \\
\hline TKFEN & 0.04807 & 0.04382 & 0.00060 \\
\hline TOASO & -0.15672 & -0.01247 & 0.00052 \\
\hline TUPRS & 0.05561 & 0.05477 & 0.00043 \\
\hline YHYAO & -0.02562 & -0.01633 & 0.00070 \\
\hline ТТКОМ & 0.02509 & 0.02698 & 0.00067 \\
\hline TCELL & 0.00130 & 0.00113 & 0.00046 \\
\hline VAKBN & -0.13262 & -0.04545 & 0.00068 \\
\hline YKBNK & -2.49412 & -0.02404 & 0.00056 \\
\hline
\end{tabular}

Tablo 5 Markov zincirleri modelleri ile hesaplanan ortalama getiriler ile basit getirileri göstermektedir. Bakıldığında EKGYO hissesine ait Markov beklenen getiri pozitifken, basit ortalama getiri hesabına göre negatiftir. Genel olarak hisselerin beklenen getirilerinin işaretleri aynı olmasına rağmen getiri büyüklükleri farklılık göstermektedir.

Çalışmanın başında da ifade edildiği gibi basit anlamda hesaplanan ortalama getirilerde herhangi bir olasılık hesabı yoktur. Fakat Markov zincirleri modelleri durağan durum olasılıklarını hesaba katarak ortalama getiri hesaplamaktadır. Dolayısıyla Markov zincirleri modelleriyle hesaplanan getirilerin portföy analizinde daha etkin sonuçlar üretmesi beklenmektedir. Örneğin portföy analizi aşamasında basit ortalama ile hesaplanan getiri kullanılmış olursa EREGL hissesinin \%0.02714 ortalama getiri sağladığı düşünülecektir. Fakat olasılıklarla hesaplanan Markov zincirlerine göre bu hisse senedinin beklenen getirisi \%5.3694 olarak gerçekleşmiştir. Burada getirinin hem işareti değişmiş hem de çok ciddi bir kayıp hesaplanmıștır. YKBNK hissesinde de benzer bir durum söz konusudur. Burada getirinin işareti değişmese de büyüklüğü değişmiştir.

Markov getiriler ve basit getiriler elde edildikten sonraki aşamada Markowitz'in ortalama-varyans modeline göre portföyler oluşturulmuştur. Oluşturulan portföylerde Markov getirilerin kullanıldığı portföylerin her defasında basit ortalama getirili portföylerden daha etkin olduğu görülmüștür. Markov modeller her defasında aynı risk düzeyinde daha fazla getiri sağlamıştır. Hatta bu fark portföy riskinin yüksek olduğu durumlarda daha fazladir.

Ortalama varyans modeline göre optimize edilen portföylerde sabit bir portföy riskine karşılık maksimum getiri elde edilmeye çalışılmıştır. Tablo 6'daki modellerde sadece belirlenmiş risk kısıtı ile toplam ağırlıkların bire eşit olma kısıtı kullanılmıştır. Tablo 7'de özetlenen modellerde ise riskin dağıtılması amacı ile her bir hisse senedine maksimum 0.35 ağırlık verilmesi kısıtı eklemiştir. Böylelikle en az 4 hisse senedine yatırım yapılması ve çeşitlendirme yoluyla riskin dağıtılması amaçlanmıştır. Aşağıdaki tabloda optimize edilen portföylerin bilgileri ve hisse senetlerine yapılan yatırımın ağırlıkları verilmiştir. 
Tablo 6: Markov Modelleri ve Basit Getiri ile Oluşturulmuş Portföy Getirileri

\begin{tabular}{lccc}
\hline & $\begin{array}{c}\text { Portföy } \\
\text { Riski }\end{array}$ & $\begin{array}{c}\text { Markov } \\
\text { Getirili } \\
\text { Model }\end{array}$ & $\begin{array}{c}\text { Basit } \\
\text { Getirili } \\
\text { Model }\end{array}$ \\
\hline (risk1) & 0.0003354 & 0.374617 & 0.06787 \\
(risk2) & 0.0003690 & 0.573571 & 0.07964 \\
(risk3) & 0.0004059 & 0.792424 & 0.08850 \\
(risk4) & 0.0004464 & 1.027264 & 0.09772 \\
(risk5) & 0.0004911 & 1.027264 & 0.10785 \\
(risk6) & 0.0005402 & 1.027264 & 0.11900 \\
(risk7) & 0.0005942 & 1.027264 & 0.13126 \\
(risk8) & 0.0006536 & 1.027264 & 0.14752 \\
(risk9) & 0.0007190 & 1.027264 & 0.15959 \\
(risk10) & 0.0007909 & 1.027264 & 0.17591 \\
(risk11) & 0.0008700 & 1.027264 & 0.18771 \\
\hline
\end{tabular}

Tablo6'da portföy riski 0.0003354'den başlamak üzere, her defasında bu risk \%10 arttırılarak oluşturulan portföylerin amaç fonksiyonu değerleri (portföy beklenen getirisi) gösterilmektedir. Örneğin 0.0003354 veri risk ile oluşturulan Markov getirili model portföyün getirisi 0.37461 olarak gerçekleşirken, basit modelin getirisi aynı risk düzeyi için 0.06787 olarak gerçekleşmiştir. Diğer tüm risk düzeyleri için Markov modeli portföylerin getirisi basit model getirilerinden yüksek hesaplanmıştır. Markov model getirileri ile oluşturulan portföylerde riskin 0.000446'nın üzerine çıması portföy getirisinde herhangi bir iyileştirme oluşturmadığı gözlenmiştir. Basit getirili modele riskle birlikte getiri de artmaktadır ama getiri seviyesi hep Markov model portföylerin altında kalmaktadır. İki getiri hesaplaması temelinde oluşturulan portföylerde hangi hisse senetlerin olduğu da önemlidir. Bununla ilgili bilgiler Tablo 8'den itibaren Ek-A'da verilmiştir.

Tablo8'deki (EK-A) ağırlıklar basit getirili modellerin 11 risk düzeyine bağlı olarak sahip oldukları hisse senedi ağırlıklarıdır. 0.0003690 risk düzeyi (risk2) için portföy BIMAS ve SODA hisse senetlerine yatırım yapmayı öngörmektedir. Buna bağlı beklenen getiri ise 0.07964 olarak hesaplanmıştır. Bundan sonraki tüm risk seviyeleri için yatırım ağırlığı farklı olsa da portföy için en optimal yatırım PGSUS ve SODA hisse senetlerine yatırım yapmaktır.
Model en yüksek risk seviyesinde ise sadece PGSUS'sa yatırım yapmayı öngörmektedir.

Tablo9'de (EK-A) Markov getirileri ile oluşturulan ortalama-varyans modellerin risk düzeylerine göre hisselerin portföy içindeki ağırlıkları verilmiștir. Risk1, risk2 ve risk3 düzeyleri için BIMAS ve EKGYO hisselerine yatırımı öngören model diğer risk düzeylerinde EKGYO ve DOHOL hisselerine yatırımı öngörmektedir. Çeşitlendirme açısından baktığımızda Markov ortalama-varyans modelleri basit getirili ortalama-varyans modellerinden daha iyi sonuç vermediği görülmektedir. Her iki hesaplama türünde de optimal portföyler iki hisse senedi üzerinden oluşturulmaktadır. Modeller arasındaki fark portföy içindeki hisse senetleri bazında ortaya çıkmaktadır. Basit getirili modeller BIMAS, PGSUS ve SODA hisselerine yatırımı öngörürken, Markov temelli modeller BIMAS, DOHOL ve EKGYO hisselerine yatırımı öngörmektedir.

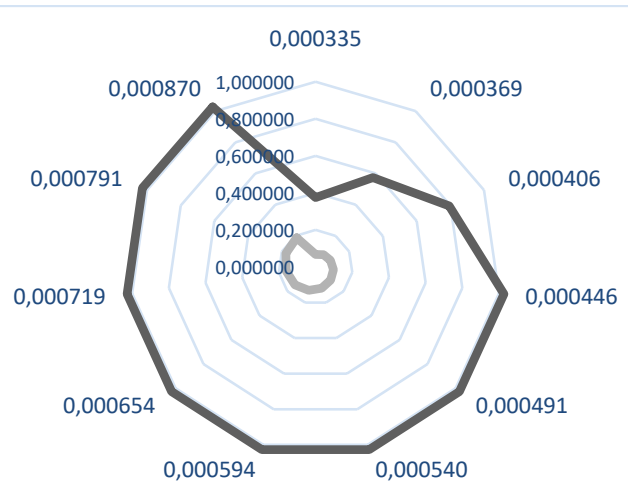

Şekil 1: Markov Getirili ve Basit Getirili Modellerin Etkin Sınırları

Şekil 1, en üstte 0.000335 risk ile başlayarak ve saat yönüne doğru risk oranını arttırarak daire şeklinde Markov getirili modellerin ve basit getirili modellerin etkin sinırlarını göstermektedir. İç kısımdaki daire basit getirili modellerden elde edilmiş etkin sınırı göstermektedir. Şekilden rahatlıkla anlaşılacağı gibi basit getirili modeller hiçbir risk seviyesinde Markov getirili modellerin etkin sınırını aşamamıştır. Tüm risk seviyeleri için Markov temelli modeller, basit getirili modellerden daha etkin portföyler üretmiștir. 
Aynı durum çeşitlendirilmiş modeller için de geçerli midir? Oluşturulacak portföy modelleri çeşitlendirmeye zorlanırsa durum ne olur? Daha çok hisseye yatırım yapılırsa iki modelin getiri-risk performansı nasıl etkilenir? $\mathrm{Bu}$ soruların cevaplarını bulmak için ortalamavaryans modeline $w \leq 0.35$ kısıtı eklenmiştir. $\mathrm{Bu}$ kısıt sayesinde model en az üç hisse senedine yatırım yapacaktır. Așağıdaki tabloda $w \leq 0.35 \quad$ kısitlı modellerin sonuçları özetlenmiştir.

Tablo 7: Çeşitlendirilmiş Portföylerin Risk Düzeyleri ve Getiri Düzeyleri

\begin{tabular}{ccc}
\hline $\begin{array}{c}\text { Portföy } \\
\text { Riski }\end{array}$ & Markov Getirili Model & Basit Getirili Model \\
\hline 0.0003354 & 0.128079 & 0.05511 \\
0.0003690 & 0.429185 & 0.06579 \\
0.0004059 & 0.532732 & 0.07755 \\
0.0004464 & 0.646634 & 0.09048 \\
0.0004911 & 0.771926 & 0.10402 \\
0.0005402 & 0.847708 & 0.11576 \\
0.0005942 & 0.871378 & 0.12841 \\
0.0006536 & 0.878745 & 0.14233 \\
0.0007190 & 0.87878 & 0.15378 \\
0.0007909 & 0.87878 & 0.16391 \\
0.0008700 & 0.87878 & 0.16421 \\
\hline
\end{tabular}

Tablo7, belirlenmiş risk düzeylerine bağlı olarak ortalama varyans modellerinin getirilerini göstermektedir. Karşılaştırma yapıldığında tüm risk düzeyleri için Markov getirili modellerin basit getirili modellere göre daha yüksek getiriye sahip olduğu görülmektedir. Markov getirili modellerde risk düzeyini 0.0006536 seviyesinin üzerine çıkartmak getiri oranını artırmamaktadır. Basit getirili modeller için ise risk seviyesi 0.0008700 düzeyinde maksimum getiri sağlanmaktadır.

Tablo10'daki (EK-A) Basit getirili modellerin hisse senedi ağırlıklarına göre BIMAS, KCHOL, PGSUS, KOZAL, DOHOL ve SODA şirketlerin hisse senetlerine yatırım yapılmalıdır. Yani risk düzeyine göre basit getirili model yukarıda siralanan hisse senetlerinin kombinasyonunu önermektedir.

Tablo11 (EK-A) Markov getirili modellerin risk düzeyine bağlı hisselerin ağırlıklarını göstermektedir. Markov getirili modeller
BIMAS, DOHOL, EKGYO, FROTO, KCHOL, KOZAL ve SODA hisselerine yatırımı önermektedir. Modeller tüm risk düzeyleri için EKGYO hissesine minimum 0.0781 oranında yatırım yapmayı tavsiye etmektedir. Bir bütün olarak karşılaștırıldığında Markov getirili modelde toplam yedi hisse yatırım için seçilirken basit getirili modeller altı hisse önermektedir. $\mathrm{Bu}$ hisselerden beş tanesi ağırlıkları farklı olsa da aynı hisselerdir. Son olarak bu modellerin etkin sınırları karşılaştırmıștır.

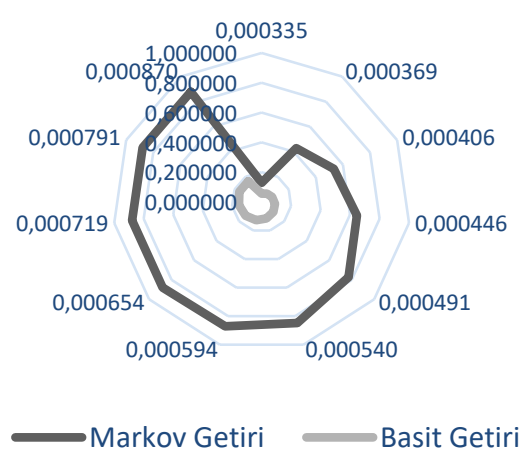

Şekil 2: Çeşitlendirilmiş Portföylerde Markov ve Basit Getirili Modellerin Etkin Sınırları

Şekil $2 w \leq 0.35$ kısıtlı modellerin etkin sınırları aynı grafikte gösterilmiştir. Yine en düşük risk 0.000335 olmak üzere ve saat yönüne doğru risk seviyesinin artması koșulu ile, Markov getirili modellerin etkin sinırı daima basit getirili modellerin etkin sınırından yüksek olmuştur. Etkin sınırların birbirine en yaklaştığı nokta minimum risk noktasıdır. Bu nokta dışında etkin sınırlar arasındaki alan sürekli artma eğilimindedir.

Toparlanacak olursa, yapılan analizler ıșığında Markov getirili modellerin basit getirili modellere oranla daha iyi getiri hesapladığını söyleyebiliriz. Çeşitlendirme açısından her iki model de benzer sonuçlar üretmiştir. Tabii ki yukarıda hesaplanan ortalama varyans modellerinde sadece birinci ve ikinci momentler kullanılmıștır. Literatürde daha yüksek momentler kullanan modeller de mevcuttur. Teknik analiz yaparken daha yüksek momentli modellerde Markov getirili modellerin performansı ayrıca incelenmelidir. Ayrıca yatırımcı bir yatırım kararında hisse 
senetlerinin pozitif getiriye sahip olmasını göz önünde bulundururken, hisse senelerinin oynaklıklarını da göz önünde bulunduracaktır. Literatürde oynaklık ölçüsü olarak çoğunlukla standart sapma veya varyans değerleri kullanılmaktadır. Getiri hesaplarının yanında farklı risk (oynaklık) ölçüleri de kullanılabilir. Son olarak portföy oluştururken getiri ve risk ölçütleri kadar riskin doğru bir şekilde dağıtılması da önemlidir. Bunun için modele kovaryans matrisleri dahil edilebilir veya negatif korelasyonlu hisseler seçilerek risk dağıtılabilir. Fakat tüm hisselerin aynı makro ekonomik faktörlerden etkilenmesi beklendiği için hisseler arasındaki korelasyon katsayısı genelde pozitif gerçekleşmektedir.

\section{SONUÇ}

Portföy teorisi Markowitz'in 1952 yllındaki makalesinden sonra muazzam bir ilgi görmüş ve yatırımcılar piyasa getirisinin üzerinde kar elde edebilmek için birçok teknik yöntem kullanmıştır. $\quad \mathrm{Bu}$ doğrultuda klasik maksimizasyon teknikleri 1990 'lı yılların sonuna kadar oldukça yoğun kullanılmıştır. 2000'li yılların başından itibaren portföy teorisi yeni bir yön bulmuştur ve portföy seçiminde getiri dağılımları ve olasılık hesapları çok daha fazla kullanılır hale gelmiştir. Buna paralel olarak birçok yeni teknik önerilmiştir. Markov zincirleri modelleri bu tekniklerden bir tanesidir. Bu çalışma yapılırken de hisse senetlerin geçmiş değerlerinden faydalanarak, verimlilikleri Markov zincirleri modelleri ile modellenmiştir ve geçiş olasılıkları matrisi yardımıyla durağan durum olasılıkları elde edilmiștir. Yapılan analizler sonucunda BIST30 endeksinde işlem gören 28 hisse senedinin verimlilik oranları ve yatırım getirileri hesaplanmıştır. Buna göre, Markov getirili modeller basit getirili modellere göre tüm risk düzeyleri için daha yüksek bir getiri oranına sahip olmuştur. Riski dağıtmak konusunda hem basit getirili modeller hem de Markov getirili modeller benzer sonuçlar üretmiştir. Çeşitlendirilmiş portföylerde Markov getirili modellerin performansını ölçmek amacıyla, probleme maksimum yatırım oranı kısıtı eklenmiştir ve sonuçta Markov modellerin basit getirili modellerden daha etkin portföyler oluşturduğu, etkin sinırlar yardımıyla gösterilmiștir. Çeşitlendirilmiş portföyler için Markov getirili modeller toplam yedi farklı hisse senedine yatırımı tavsiye ederken basit getirili modeller altı farklı hisse senedi tavsiye etmiştir. Bu hisselerden beş tanesi ortaktır. Yani çeşitlendirme açısından yine her iki getiri hesaplama yöntemi benzer sonuçlar üretmiştir. Bir bütün olarak değerlendirildiğinde Markov getirili modellerin getiri tahmin etmek konusunda daha başarılı olduğunu fakat çeşitlendirme açısından basit getirili modellerden çok az ayrıştığını görmekteyiz. Markov zincirleri olasılığa dayalı getiriler hesapladığı için, basit getirilere kıyasla bu getirilerin daha güvenilir olduğu sonucuna varılmıştır. Daha önce değinildiği gibi geçmiş verilerden elde edilmiş bir beklenen getirinin yatırım dönemi için de gerçekleşeceğini garanti eden hiçbir bulgu yoktur. Tahmin içeren tüm beklenen getiri hesaplamalarına ancak belli bir olasılıkla güvenebiliriz. Dolayısıyla Markov zincirleri modelleri gibi temelinde olasılık olan yöntemlerden elde edilecek tahminlerin daha tutarlı olacağı düşünülmektedir.

\section{KAYNAKÇA}

Aksoy, A. G., ve Tanriöven, C. (2007). Sermaye Piyasası Yatırım Araçları Ve Analizi. Gazi Kitabevi.

Bailey, W., ve Chung, Y. P. (1995). Exchange Rate Fluctuations, Political Risk, and Stock Returns: Some Evidence From an Emerging
Market. Journal of Financial and Quantitative Analysis, 30(4), 541-561.

Bali, T. G., Cakici, N., Yan, X., ve Zhang, Z. (2005). Does Idiosyncratic Risk Really Matter?. The Journal of Finance, 60(2), 905-929. 
Barakat, M. R., Elgazzar, S. H., ve Hanafy, K. M. (2016). Impact of Macroeconomic Variables on Stock Markets: Evidence from Emerging Markets. International Journal of Economics and Finance, 8(1), 195-207.

Bae, K., Kang, H., ve Kang, J. (2020). Can Fat-Tail Create the Momentum and Reversal?. Applied Economics, 1-14.

Buser, S. A. (1977). Mean-Variance Portfolio Selection With Either a Singular or Nonsingular Variance-Covariance Matrix. Journal of Financial and Quantitative Analysis, 12(3), 347-361.

Cyert, R. M., ve Thompson, G. L. (1968). Selecting a Portfolio of Credit Risks by Markov Chains. the Journal of Business, 41(1), 39-46.

Demirtaş, Ö., ve Güngör, Z. (2004). Portföy Yönetimi ve Portföy Seçimine Yönelik Uygulama. Journal of Aeronautics and Space Technologies, 1(4), 103-109.

Dooley, M. P., ve Isard, P. (1980). Capital Controls, Political Risk, and Deviations from Interest-Rate Parity. Journal of Political Economy, 88(2), 370-384.

Doubleday, K. J., ve Esunge, J. N. (2011). Application of Markov Chains to Stock Trends. Journal of Mathematics and Statistics, 7(2), 103-106.

Eom, C., Karzojı, T., ve Scalas, E. (2019). Fat Tails in Financial Return Distributions Revisited: Evidence from the Korean Stock Market. Physica A: Statistical Mechanics and Its Applications, 526, 121055.

Fabozzi, F. J., Kolm, P. N., Pachamanova, D. A., ve Focardi, S. M. (2007). Robust Portfolio Optimization and Management. John Wiley \& Sons.

Fu, F. (2009). Idiosyncratic Risk and the CrossSection of Expected Stock Returns. Journal of Financial Economics, 91(1), 24-37.

Glover, B., ve Levine, O. (2017). Idiosyncratic Risk and the Manager. Journal of Financial Economics, 126(2), 320-341.
Goyal, A., ve Santa-Clara, P. (2003). Idiosyncratic Risk Matters!. The Journal of Finance, 58(3), 975-1007.

Gujarati, D. N., Porter, D. C., ve Gunasekar, S. (2012). Basic Econometrics. Tata Mcgraw-Hill Education.

Hamilton, J. D. (1994). Time Series Analysis (Vol. 2). Princeton: Princeton University Press.

Head, G. L. (1967). An Alternative to Defining Risk as Uncertainty. Journal of Risk and Insurance, 205-214.

Huang, W., Liu, Q., Rhee, S. G., ve Zhang, L. (2010). Return Reversals, Idiosyncratic Risk, and Expected Returns. The Review of Financial Studies, 23(1), 147-168.

Ibrahim, M. (1999). Macroeconomic Variables and Stock Prices In Malaysia: an Empirical Analysis. Asian Economic Journal, 13(2), 219231.

Kadir, T. U. N. A., Mehmet, T. U. R. K., ve Alper, 0. Z. U. N. (2014). Uluslararası Portföy Yönetiminde Rejim Geçişken Karar Destek Modelleri: Gelişmekte Olan Menkul Kiymet Piyasaları Üzerine Bir Uygulama. İşletme ve İktisat Çalışmaları Dergisi, 2(2), 27-43.

Klaassen, P., ve Van Eeghen, I. (2009). Economic Capital: How It Works, and What Every Manager Needs to Know. Elsevier.

Kwon, C. S., ve Shin, T. S. (1999). Cointegration and Causality Between Macroeconomic Variables and Stock Market Returns. Global Finance Journal, 10(1), 71-81.

Lintner, John. (1965). "The Valuation of Risk Assets and The Selection of Risky Investments in Stock Portfolios and Capital Budgets." Review of Economics and Statistics. 47:1, Pp. 13-37.

Liu, S. Y. W. S., Wang, S. Y., ve Qiu, W. 2. (2003). Mean-Variance-Skewness Model for Portfolio Selection with Transaction Costs. International Journal of Systems Science, 34(4), 255-262.

Markowitz, H. M. (1978). Portfolio Selection. J. Finance,1952,7,77-91. 
Mcqueen, G., ve Thorley, S. (1991). Are Stock Returns Predictable? A Test Using Markov Chains. The Journal of Finance, 46(1), 239-263.

Mehr-Un-Nisa, M. N., ve Nishat, M. (2011). The Determinants of Stock Prices In Pakistan. Asian Economic and Financial Review, 1(4), 276-291.

Mishkin, F. (2007). Money, Banking and Financial Markets. New Horizons, Paris, France. Mwaurah, I., Muturi, W., Ve Waititu, A. (2017). The Influence of Financial Risk on Stock Returns. International Journal of Scientific and Research Publications, 7(5), 418-430.

Rjoub, H., Civcir, I., ve Resatoglu, N. G. (2017). Micro And Macroeconomic Determinants of Stock Prices: The Case of Turkish Banking
Sector. Romanian Journal of Economic Forecasting, 20(1), 150-166.

Sharpe, W. F. (1963). A Simplified Model for Portfolio Analysis. Management Science, 9(2), 277-293.

Singh, D. (2010). Causal Relationship Between Macro-Economic Variables and Stock Market: A Case Study For India. Pakistan Journal of Social Sciences (Pjss), 30(2).

Officer, R. R. (1972). The Distribution of Stock Returns. Journal of the American Statistical Association, 67(340), 807-812.

Williams, R. T. (2011). An Introduction to Trading in the Financial Markets: Technology: Systems, Data, and Networks. Academic Press. 


\section{S. ÇAM}

\section{EK-A}

Tablo 8: Basit Getirili Portföylerin Hisse Senetleri Ağırlıkları

\begin{tabular}{|c|c|c|c|c|c|c|c|c|c|c|c|}
\hline Risk/Ağırlık & Risk1 & Risk2 & Risk3 & Risk4 & Risk5 & Risk6 & Risk7 & Risk8 & Risk9 & Risk10 & Risk11 \\
\hline AKBNK & & & & & & & & & & & \\
\hline $\begin{array}{c}\cdots \\
\text { ASELS }\end{array}$ & ... & $\ldots$ & $\cdots$ & $\cdots$ & $\cdots$ & $\cdots$ & $\cdots$ & $\cdots$ & $\cdots$ & $\ldots$ & $\cdots$ \\
\hline BIMAS & & 0.0403 & & & & & & & & & \\
\hline $\begin{array}{c}\cdots \\
\text { KOZAA }\end{array}$ & $\cdots$ & $\ldots$ & $\cdots$ & $\ldots$ & $\cdots$ & $\ldots$ & $\cdots$ & $\cdots$ & $\cdots$ & $\cdots$ & $\cdots$ \\
\hline $\begin{array}{l}\text { PGSUS } \\
\text { PETKM }\end{array}$ & 1 & & 0.0705 & 0.1569 & 0.2518 & 0.3563 & 0.4712 & 0.5976 & 0.7366 & 0.8895 & 1 \\
\hline $\begin{array}{c}\text { SAHOL } \\
\text { SODA }\end{array}$ & & 0.9597 & 0.9295 & 0.8431 & 0.7482 & 0.6437 & 0.5288 & 0.4024 & 0.2634 & 0.1105 & \\
\hline $\begin{array}{c}\cdots \\
\text { YKBNK }\end{array}$ & ... & $\cdots$ & $\ldots$ & $\cdots$ & ... & $\cdots$ & $\cdots$ & $\cdots$ & $\cdots$ & $\cdots$ & $\cdots$ \\
\hline Toplam & 1 & 1 & 1 & 1 & 1 & 1 & 1 & 1 & 1 & 1 & 1 \\
\hline
\end{tabular}

Tablo 9: Markov Getirili Portföylerin Hisse Senetleri Ağırlıkları

\begin{tabular}{|c|c|c|c|c|c|c|c|c|c|c|c|}
\hline Risk/Ağırlık & Risk1 & Risk2 & Risk3 & Risk4 & Risk5 & Risk6 & Risk7 & Risk8 & Risk9 & Risk10 & Risk11 \\
\hline AKBNK & & & & & & & & & & & \\
\hline $\begin{array}{c}\cdots \\
\text { ASELS }\end{array}$ & $\ldots$ & $\ldots$ & $\ldots$ & ... & ... & ... & ... & ... & $\cdots$ & $\ldots$ & $\cdots$ \\
\hline BIMAS & 0.6655 & 0.4623 & 0.2388 & & & & & & & & \\
\hline DOHOL & & & & 0.0034 & 0.0034 & 0.0034 & 0.0034 & 0.0034 & 0.0034 & 0.0034 & 0.0034 \\
\hline EKGYO & 0.3345 & 0.5377 & 0.7612 & 0.9966 & 0.9966 & 0.9966 & 0.9966 & 0.9966 & 0.9966 & 0.9966 & 0.9966 \\
\hline $\begin{array}{c}\cdots \\
\text { YKBNK }\end{array}$ & $\ldots$ & $\ldots$ & $\cdots$ & $\cdots$ & $\cdots$ & $\cdots$ & $\cdots$ & $\cdots$ & $\ldots$ & $\cdots$ & $\cdots$ \\
\hline Toplam & 1 & 1 & 1 & 1 & 1 & 1 & 1 & 1 & 1 & 1 & 1 \\
\hline
\end{tabular}

Tablo 10 Basit Getirili Çeşitlendirilmiş Portföylerin Hisse Senedi ağırlıkları

\begin{tabular}{|c|c|c|c|c|c|c|c|c|c|c|c|}
\hline Risk/Ağırlık & Risk1 & Risk2 & Risk3 & Risk4 & Risk5 & Risk6 & Risk7 & Risk8 & Risk9 & Risk10 & Risk11 \\
\hline$A K B N K$ & & & & & & & & & & & \\
\hline $\begin{array}{c}\cdots \\
A S E L S\end{array}$ & ... & ... & $\ldots$ & ... & ... & ... & ... & ... & ... & ... & ... \\
\hline BIMAS & 0.3500 & 0.3500 & 0.3500 & 0.3500 & 0.3327 & 0.2399 & 0.1340 & 0.0176 & & & \\
\hline DOHOL & & & & & & 0.0601 & 0.1660 & 0.2824 & 0.3500 & 0.3500 & 0.3500 \\
\hline KCHOL & 0.2917 & 0.2246 & 0.1509 & 0.0698 & & & & & & & \\
\hline $\begin{array}{l}\text { KOZAL } \\
\text { KOZAA }\end{array}$ & & & & & & & & & 0.0971 & 0.2941 & 0.3000 \\
\hline $\begin{array}{l}\text { PGSUS } \\
\text { PETKM }\end{array}$ & 0.0083 & 0.0754 & 0.1491 & 0.2302 & 0.3173 & 0.3500 & 0.3500 & 0.3500 & 0.3500 & 0.3500 & 0.3500 \\
\hline SAHOL & & & & & & & & & & & \\
\hline SODA & 0.3500 & 0.3500 & 0.3500 & 0.3500 & 0.3500 & 0.3500 & 0.3500 & 0.3500 & 0.2029 & 0.0059 & \\
\hline $\begin{array}{c}\cdots \\
Y K B N K\end{array}$ & $\cdots$ & ... & ... & ... & ... & ... & $\ldots$ & ... & $\ldots$ & $\ldots$ & ... \\
\hline Toplam & 1 & 1 & 1 & 1 & 1 & 1 & 1 & 1 & 1 & 1 & 1 \\
\hline
\end{tabular}

Not: Yukarıdaki sonuçlar $w \leq 0.35$ ağırlık kısıtı altında elde edilmiștir. 
Tablo 11 Markov Getirili Çeşitlendirilmiş Portföylerin Hisse Senedi ağırlıkları

\begin{tabular}{|c|c|c|c|c|c|c|c|c|c|c|c|}
\hline Risk/Ağırlık & Risk1 & Risk2 & Risk3 & Risk4 & Risk5 & Risk6 & Risk7 & Risk8 & Risk9 & Risk10 & Risk11 \\
\hline$A K B N K$ & & & & & & & & & & & \\
\hline$\stackrel{\cdots}{A S E L S}$ & $\ldots$ & ... & $\cdots$ & $\ldots$ & ... & $\ldots$ & ... & $\ldots$ & $\ldots$ & $\cdots$ & $\ldots$ \\
\hline BIMAS & 0.3500 & 0.3500 & 0.3500 & 0.3500 & 0.3500 & 0.1955 & & & & & \\
\hline DOHOL & & 0.0274 & 0.1098 & 0.2003 & 0.2999 & 0.3500 & 0.3500 & 0.3500 & 0.3500 & 0.3500 & 0.3500 \\
\hline EKGYO & 0.0781 & 0.3500 & 0.3500 & 0.3500 & 0.3500 & 0.3500 & 0.3500 & 0.3500 & 0.3500 & 0.3500 & 0.3500 \\
\hline FROTO & & & & & & 0.1045 & 0.2572 & 0.0012 & & & \\
\hline KCHOL & 0.3500 & 0.2726 & 0.1902 & 0.0997 & 0.0001 & & & & & & \\
\hline KOZAL & & & & & & & 0.0428 & 0.2988 & 0.3000 & 0.3000 & 0.3000 \\
\hline SODA & 0.2219 & & & & & & & & & & \\
\hline $\begin{array}{c}\cdots \\
\text { YKBNK }\end{array}$ & $\ldots$ & ... & $\ldots$ & $\ldots$ & $\ldots$ & $\ldots$ & $\ldots$ & $\ldots$ & $\ldots$ & $\ldots$ & $\ldots$ \\
\hline Toplam & 1 & 1 & 1 & 1 & 1 & 1 & 1 & 1 & 1 & 1 & 1 \\
\hline
\end{tabular}

Tablo 12: Korelasyon Katsayıları

\begin{tabular}{|c|c|c|c|c|c|c|c|c|c|c|c|c|c|c|c|c|c|c|c|c|c|c|c|c|c|c|c|c|c|}
\hline & & \begin{tabular}{|l|}
$H 1$ \\
\end{tabular} & \begin{tabular}{|l|}
$\mathrm{H} 2$ \\
\end{tabular} & $\mathrm{H3}$ & $\mathrm{H} 4$ & H5 & \begin{tabular}{|l|}
$H 6$ \\
\end{tabular} & \begin{tabular}{|l|}
$\mathrm{H7}$ \\
\end{tabular} & $\mathrm{H} 8$ & \begin{tabular}{|l|}
$\mathrm{H}$ \\
\end{tabular} & \begin{tabular}{|l|}
$\mathrm{H} 1 \mathrm{O}$ \\
\end{tabular} & H11 & \begin{tabular}{|l|}
$H 12$ \\
\end{tabular} & H13 & H14 & H15 & \begin{tabular}{|l|l}
$H 16$ & \\
\end{tabular} & H17 & H18 & \begin{tabular}{|l|l}
$H 19$ & $H$
\end{tabular} & $\mathrm{H} 2 \mathrm{O}$ & $H 21$ & H22 & H23 & $\mathrm{H} 24$ & H25 & $\mathrm{H} 26$ & H27 & $H 28$ \\
\hline AKBNK & $\mathrm{H} 1$ & 1.00 & & & & & & & & & & & & & & & & & & & & & & & & & & & \\
\hline ARCLK & $\mathrm{H} 2$ & \begin{tabular}{|l|l|}
0.37 \\
\end{tabular} & \begin{tabular}{|l|}
1.00 \\
\end{tabular} & & & & & & & & & & & & & & & & & & & & & & & & & & \\
\hline ASELS & $\mathrm{H3}$ & \begin{tabular}{|l|l|}
0.52 \\
\end{tabular} & \begin{tabular}{|l|l|l|l|} 
\\
\end{tabular} & 1.00 & & & & & & & & & & & & & & & & & & & & & & & & & \\
\hline BIMAS & $\mathrm{H} 4$ & \begin{tabular}{|l|l|}
0.14 \\
\end{tabular} & \begin{tabular}{|l|l|}
0.21 \\
\end{tabular} & \begin{tabular}{|l|l|}
0.11 \\
\end{tabular} & 1.00 & & & & & & & & & & & & & & & & & & & & & & & & \\
\hline DOHOL & H5 & \begin{tabular}{|l|}
0.29 \\
\end{tabular} & \begin{tabular}{|l|}
0.22 \\
\end{tabular} & 0.30 & 0.02 & 1.00 & & & & & & & & & & & & & & & & & & & & & & & \\
\hline EKGYO & H6 & \begin{tabular}{|l|}
0.50 \\
\end{tabular} & 0.31 & 0.47 & 0.16 & \begin{tabular}{|l|}
0.27 \\
\end{tabular} & \begin{tabular}{|l|l|} 
\\
\end{tabular} & & & & & & & & & & & & & & & & & & & & & & \\
\hline EREGL & $\mathrm{H7}$ & \begin{tabular}{|l|l|}
0.32 \\
\end{tabular} & \begin{tabular}{|l|l|}
0.24 \\
\end{tabular} & 0.34 & 0.12 & \begin{tabular}{|l|}
0.13 \\
\end{tabular} & \begin{tabular}{|l|}
0.31 \\
\end{tabular} & \begin{tabular}{|l|}
1.00 \\
\end{tabular} & & & & & & & & & & & & & & & & & & & & & \\
\hline FROTO & $\mathrm{H} 8$ & 0.27 & \begin{tabular}{|l|l|} 
\\
\end{tabular} & 0.30 & 0.26 & \begin{tabular}{|l|} 
\\
\end{tabular} & \begin{tabular}{|l|} 
\\
\end{tabular} & \begin{tabular}{|l|}
0.29 \\
\end{tabular} & 1.00 & & & & & & & & & & & & & & & & & & & & \\
\hline GARAN & H9 & \begin{tabular}{|l|}
0.88 \\
\end{tabular} & \begin{tabular}{|l|l|}
0.40 \\
\end{tabular} & 0.54 & 0.17 & \begin{tabular}{|l|}
0.31 \\
\end{tabular} & \begin{tabular}{|l|l|}
0.52 \\
\end{tabular} & \begin{tabular}{|l|}
0.30 \\
\end{tabular} & 0.25 & \begin{tabular}{|l|}
1.00 \\
\end{tabular} & & & & & & & & & & & & & & & & & & & \\
\hline ISCTR & $\mathrm{H} 10$ & \begin{tabular}{|l|l|}
0.73 \\
\end{tabular} & \begin{tabular}{|l|}
0.37 \\
\end{tabular} & 0.47 & 0.16 & \begin{tabular}{|l|}
0.30 \\
\end{tabular} & \begin{tabular}{|l|l|}
0.48 \\
\end{tabular} & \begin{tabular}{|l|}
0.33 \\
\end{tabular} & 0.27 & \begin{tabular}{|l|l|}
0.77 \\
\end{tabular} & 1.00 & & & & & & & & & & & & & & & & & & \\
\hline KRDMD & $\mathrm{H} 11$ & \begin{tabular}{|l|l|}
0.47 \\
\end{tabular} & \begin{tabular}{|l|l|l|l} 
\\
\end{tabular} & \begin{tabular}{|l|l|}
0.51 \\
\end{tabular} & 0.13 & \begin{tabular}{|l|l|}
0.23 \\
\end{tabular} & \begin{tabular}{|l|l|}
0.43 \\
\end{tabular} & \begin{tabular}{|l|l|}
0.61 \\
\end{tabular} & \begin{tabular}{|l|l|}
0.29 \\
\end{tabular} & \begin{tabular}{|l|}
0.46 \\
\end{tabular} & \begin{tabular}{|l|}
0.47 \\
\end{tabular} & 1.00 & & & & & & & & & & & & & & & & & \\
\hline KCHOL & H12 & \begin{tabular}{|l|l|}
0.48 \\
\end{tabular} & \begin{tabular}{|l|l|}
0.49 \\
\end{tabular} & \begin{tabular}{|l|l|}
0.38 \\
\end{tabular} & \begin{tabular}{|l|}
0.25 \\
\end{tabular} & \begin{tabular}{|l|l|}
0.23 \\
\end{tabular} & \begin{tabular}{|l|}
0.36 \\
\end{tabular} & \begin{tabular}{|l|l|}
0.33 \\
\end{tabular} & 0.42 & \begin{tabular}{|l|}
0.49 \\
\end{tabular} & \begin{tabular}{|l|}
0.48 \\
\end{tabular} & $\begin{array}{l}0.41 \\
\end{array}$ & \begin{tabular}{|l|l|}
1.00 \\
\end{tabular} & & & & & & & & & & & & & & & & \\
\hline KOZAL & H13 & \begin{tabular}{|l|l|}
0.26 \\
\end{tabular} & \begin{tabular}{|l|l|}
0.22 \\
\end{tabular} & \begin{tabular}{|l|l|}
0.33 \\
\end{tabular} & 0.20 & \begin{tabular}{|l|l|}
0.24 \\
\end{tabular} & \begin{tabular}{|l|}
0.25 \\
\end{tabular} & \begin{tabular}{|l|}
0.20 \\
\end{tabular} & 0.17 & \begin{tabular}{|l|l|}
0.32 \\
\end{tabular} & \begin{tabular}{|l|}
0.27 \\
\end{tabular} & 0.28 & \begin{tabular}{|l|l|}
0.21 \\
\end{tabular} & \begin{tabular}{|l|}
1.00 \\
\end{tabular} & & & & & & & & & & & & & & & \\
\hline KOZAA & $\mathrm{H} 14$ & \begin{tabular}{|l|l|}
0.32 \\
\end{tabular} & \begin{tabular}{|l|}
0.23 \\
\end{tabular} & 0.31 & 0.10 & \begin{tabular}{|l|}
0.21 \\
\end{tabular} & \begin{tabular}{|l|l|}
0.25 \\
\end{tabular} & \begin{tabular}{|l|}
0.20 \\
\end{tabular} & \begin{tabular}{|l|}
0.17 \\
\end{tabular} & \begin{tabular}{|l|}
0.36 \\
\end{tabular} & 0.30 & 0.32 & \begin{tabular}{|l|l|}
0.22 \\
\end{tabular} & \begin{tabular}{|l|}
0.72 \\
\end{tabular} & \begin{tabular}{|l|}
1.00 \\
\end{tabular} & & & & & & & & & & & & & & \\
\hline PGSUS & H15 & \begin{tabular}{|l|l|}
0.33 \\
\end{tabular} & \begin{tabular}{|l|}
0.24 \\
\end{tabular} & \begin{tabular}{|l|}
0.41 \\
\end{tabular} & 0.12 & \begin{tabular}{|l|}
0.26 \\
\end{tabular} & \begin{tabular}{|l|}
0.33 \\
\end{tabular} & \begin{tabular}{|l|}
0.21 \\
\end{tabular} & \begin{tabular}{|l|}
0.19 \\
\end{tabular} & \begin{tabular}{|l|}
0.37 \\
\end{tabular} & \begin{tabular}{|l|}
0.34 \\
\end{tabular} & \begin{tabular}{|l|}
0.37 \\
\end{tabular} & \begin{tabular}{|l|}
0.27 \\
\end{tabular} & \begin{tabular}{|l|}
0.38 \\
\end{tabular} & \begin{tabular}{|l|}
0.30 \\
\end{tabular} & 1.00 & & & & & & & & & & & & & \\
\hline PETKM & $\mathrm{H} 16$ & \begin{tabular}{|l|l|}
0.42 \\
\end{tabular} & \begin{tabular}{|l|l|}
0.33 \\
\end{tabular} & $\begin{array}{ll}0.44 \\
\end{array}$ & 0.12 & \begin{tabular}{|l|l|}
0.25 \\
\end{tabular} & \begin{tabular}{|l|}
0.36 \\
\end{tabular} & \begin{tabular}{|l|}
0.36 \\
\end{tabular} & \begin{tabular}{|l|l|}
0.22 \\
\end{tabular} & \begin{tabular}{|l|l|}
0.44 \\
\end{tabular} & \begin{tabular}{|l|}
0.39 \\
\end{tabular} & 0.44 & \begin{tabular}{|l|l|} 
\\
\end{tabular} & \begin{tabular}{|l|}
0.30 \\
\end{tabular} & \begin{tabular}{|l|}
0.30 \\
\end{tabular} & \begin{tabular}{|l|}
0.32 \\
\end{tabular} & \begin{tabular}{|l|l|}
1.00 \\
\end{tabular} & & & & & & & & & & & & \\
\hline SAHOL & H17 & \begin{tabular}{|l|l|}
0.74 \\
\end{tabular} & \begin{tabular}{|l|l|}
0.40 \\
\end{tabular} & \begin{tabular}{|l|}
0.46 \\
\end{tabular} & 0.26 & \begin{tabular}{|l|}
0.32 \\
\end{tabular} & \begin{tabular}{|l|}
0.49 \\
\end{tabular} & \begin{tabular}{|l|}
0.32 \\
\end{tabular} & \begin{tabular}{|l|}
0.32 \\
\end{tabular} & \begin{tabular}{|l|}
0.71 \\
\end{tabular} & \begin{tabular}{|l|}
0.64 \\
\end{tabular} & \begin{tabular}{|l|}
0.42 \\
\end{tabular} & \begin{tabular}{|l|}
0.54 \\
\end{tabular} & \begin{tabular}{|l|}
0.22 \\
\end{tabular} & \begin{tabular}{|l|l|}
0.28 \\
\end{tabular} & \begin{tabular}{|l|}
0.33 \\
\end{tabular} & \begin{tabular}{|l|l}
0.42 & 1 \\
\end{tabular} & 1.00 & & & & & & & & & & & \\
\hline SODA & $\mathrm{H} 18$ & 2 & \begin{tabular}{|l|l|}
0.04 \\
\end{tabular} & 0.12 & 0.09 & \begin{tabular}{|l|l|}
0.04 \\
\end{tabular} & \begin{tabular}{|l|}
0.10 \\
\end{tabular} & \begin{tabular}{|l|l|}
0.12 \\
\end{tabular} & \begin{tabular}{|l|}
0.08 \\
\end{tabular} & \begin{tabular}{|l|l|}
0.01 \\
\end{tabular} & 0.00 & \begin{tabular}{|l|}
0.06 \\
\end{tabular} & \begin{tabular}{|l|l|} 
\\
\end{tabular} & \begin{tabular}{|l|}
0.06 \\
\end{tabular} & \begin{tabular}{|l|l|}
0.05 \\
\end{tabular} & \begin{tabular}{|l|}
0.02 \\
\end{tabular} & \begin{tabular}{|l|l}
0.15 & 0 \\
\end{tabular} & 0.09 & \begin{tabular}{|l|}
1.00 \\
\end{tabular} & & & & & & & & & & \\
\hline SISE & \begin{tabular}{|l|l|} 
\\
\end{tabular} & 3 & \begin{tabular}{|l|}
0.28 \\
\end{tabular} & \begin{tabular}{|l|}
0.39 \\
\end{tabular} & 0.13 & \begin{tabular}{|l|l|}
0.25 \\
\end{tabular} & \begin{tabular}{|l|}
0.35 \\
\end{tabular} & \begin{tabular}{|l|l|}
0.34 \\
\end{tabular} & \begin{tabular}{|l|}
0.29 \\
\end{tabular} & \begin{tabular}{|l|}
0.33 \\
\end{tabular} & \begin{tabular}{|l|}
0.38 \\
\end{tabular} & \begin{tabular}{|l|}
0.39 \\
\end{tabular} & \begin{tabular}{|l|}
0.36 \\
\end{tabular} & \begin{tabular}{|l|}
0.19 \\
\end{tabular} & \begin{tabular}{|l|}
0.16 \\
\end{tabular} & \begin{tabular}{|l|}
0.27 \\
\end{tabular} & \begin{tabular}{|l|l}
0.34 & 0 \\
\end{tabular} & $\begin{array}{l}0.36 \\
\end{array}$ & \begin{tabular}{|l|}
0.38 \\
\end{tabular} & \begin{tabular}{|l|l|} 
\\
\end{tabular} & & & & & & & & & \\
\hline TAVHL & $\mathrm{H} 2 \mathrm{O}$ & \begin{tabular}{|l|l|}
0.13 \\
\end{tabular} & \begin{tabular}{|l|l|}
0.16 \\
\end{tabular} & \begin{tabular}{|l|}
0.16 \\
\end{tabular} & 0.18 & \begin{tabular}{|l|}
0.11 \\
\end{tabular} & \begin{tabular}{|l|}
0.21 \\
\end{tabular} & \begin{tabular}{|l|}
0.22 \\
\end{tabular} & \begin{tabular}{|l|}
0.24 \\
\end{tabular} & \begin{tabular}{|l|}
0.16 \\
\end{tabular} & \begin{tabular}{|l|}
0.16 \\
\end{tabular} & \begin{tabular}{|l|}
0.22 \\
\end{tabular} & \begin{tabular}{|l|}
0.27 \\
\end{tabular} & \begin{tabular}{|l|}
0.15 \\
\end{tabular} & \begin{tabular}{|l|l|}
0.12 \\
\end{tabular} & \begin{tabular}{|l|}
0.21 \\
\end{tabular} & \begin{tabular}{|l|l}
0.22 & 0 \\
\end{tabular} & $\begin{array}{ll}0.24 \\
\end{array}$ & \begin{tabular}{|l|}
0.17 \\
\end{tabular} & \begin{tabular}{|l|l|}
0.35 \\
\end{tabular} & \begin{tabular}{|l|}
1.00 \\
\end{tabular} & & & & & & & & \\
\hline TKFEN & $\mathrm{H} 21$ & 20 & \begin{tabular}{|l|}
0.20 \\
\end{tabular} & 0.23 & 0.17 & \begin{tabular}{|l|l|}
0.07 \\
\end{tabular} & \begin{tabular}{|l|l|}
0.27 \\
\end{tabular} & \begin{tabular}{|l|}
0.30 \\
\end{tabular} & \begin{tabular}{|l|}
0.20 \\
\end{tabular} & \begin{tabular}{|l|}
0.22 \\
\end{tabular} & \begin{tabular}{|l|}
0.16 \\
\end{tabular} & \begin{tabular}{|l|}
0.28 \\
\end{tabular} & \begin{tabular}{|l|}
0.25 \\
\end{tabular} & \begin{tabular}{|l|}
0.10 \\
\end{tabular} & \begin{tabular}{|l|l|}
0.11 \\
\end{tabular} & \begin{tabular}{|l|}
0.16 \\
\end{tabular} & \begin{tabular}{|l|l}
0.26 & 0 \\
\end{tabular} & 0.30 & \begin{tabular}{|l|}
0.23 \\
\end{tabular} & \begin{tabular}{|l|c}
0.30 & 0 \\
\end{tabular} & \begin{tabular}{|l|}
0.20 \\
\end{tabular} & 1.00 & & & & & & & \\
\hline TOASO & $\mathrm{H} 22$ & \begin{tabular}{|l|l|}
0.34 \\
\end{tabular} & \begin{tabular}{|l|l|}
0.29 \\
\end{tabular} & \begin{tabular}{|l|}
0.28 \\
\end{tabular} & 0.21 & \begin{tabular}{|l|l|}
0.19 \\
\end{tabular} & \begin{tabular}{|l|}
0.30 \\
\end{tabular} & \begin{tabular}{|l|l|}
0.25 \\
\end{tabular} & \begin{tabular}{|l|}
0.43 \\
\end{tabular} & \begin{tabular}{|l|}
0.33 \\
\end{tabular} & \begin{tabular}{|l|l|}
0.29 \\
\end{tabular} & 0.35 & \begin{tabular}{|l|l|}
0.43 \\
\end{tabular} & \begin{tabular}{|l|}
0.12 \\
\end{tabular} & \begin{tabular}{|l|l|}
0.09 \\
\end{tabular} & \begin{tabular}{|l|}
0.20 \\
\end{tabular} & \begin{tabular}{|l|l}
0.23 & 0 \\
\end{tabular} & $\begin{array}{ll}0.31 \\
\end{array}$ & \begin{tabular}{|l|}
0.06 \\
\end{tabular} & \begin{tabular}{|l|c}
0.32 & $C$ \\
\end{tabular} & \begin{tabular}{|l|l|}
0.21 \\
\end{tabular} & 0.17 & \begin{tabular}{|l|}
1.00 \\
\end{tabular} & & & & & & \\
\hline TUPRS & $\mathrm{H} 23$ & \begin{tabular}{|l|}
0.24 \\
\end{tabular} & \begin{tabular}{|l|}
0.18 \\
\end{tabular} & 0.23 & 0.13 & \begin{tabular}{|l|l|}
0.18 \\
\end{tabular} & \begin{tabular}{|l|}
0.23 \\
\end{tabular} & \begin{tabular}{|l|}
0.26 \\
\end{tabular} & \begin{tabular}{|l|}
0.19 \\
\end{tabular} & \begin{tabular}{|l|}
0.23 \\
\end{tabular} & \begin{tabular}{|l|}
0.25 \\
\end{tabular} & \begin{tabular}{|l|}
0.29 \\
\end{tabular} & \begin{tabular}{|l|l|}
0.37 \\
\end{tabular} & \begin{tabular}{|l|}
0.08 \\
\end{tabular} & \begin{tabular}{|l|}
0.04 \\
\end{tabular} & \begin{tabular}{|l|l|}
0.13 \\
\end{tabular} & \begin{tabular}{|l|l}
0.25 & 0 \\
\end{tabular} & 0.27 & \begin{tabular}{|l|}
0.11 \\
\end{tabular} & \begin{tabular}{|l|c}
0.31 \\
\end{tabular} & 0.20 & 0.18 & \begin{tabular}{|l|}
0.20 \\
\end{tabular} & \begin{tabular}{|l|}
1.00 \\
\end{tabular} & & & & & \\
\hline THYAO & $\mathrm{H} 24$ & \begin{tabular}{|l|l|}
0.48 \\
\end{tabular} & \begin{tabular}{|l|}
0.30 \\
\end{tabular} & \begin{tabular}{|l|}
0.59 \\
\end{tabular} & 0.10 & \begin{tabular}{|l|}
0.29 \\
\end{tabular} & \begin{tabular}{|l|l|}
0.42 \\
\end{tabular} & \begin{tabular}{|l|l|}
0.37 \\
\end{tabular} & \begin{tabular}{|l|}
0.24 \\
\end{tabular} & \begin{tabular}{|l|l|}
0.51 \\
\end{tabular} & \begin{tabular}{|l|}
0.46 \\
\end{tabular} & \begin{tabular}{|l|}
0.51 \\
\end{tabular} & \begin{tabular}{|l|l|}
0.38 \\
\end{tabular} & \begin{tabular}{|l|}
0.37 \\
\end{tabular} & \begin{tabular}{|l|}
0.39 \\
\end{tabular} & \begin{tabular}{|l|}
0.59 \\
\end{tabular} & \begin{tabular}{|l|l}
0.44 & 0 \\
\end{tabular} & $\begin{array}{l}0.43 \\
\end{array}$ & \begin{tabular}{|l|}
0.11 \\
\end{tabular} & \begin{tabular}{|l|c}
0.42 \\
\end{tabular} & \begin{tabular}{|l|}
0.27 \\
\end{tabular} & 0.25 & \begin{tabular}{|l|}
0.24 \\
\end{tabular} & \begin{tabular}{|l|l|}
0.22 \\
\end{tabular} & \begin{tabular}{|l|l|} 
\\
\end{tabular} & & & & \\
\hline ПТКОМ & $\mathrm{H} 25$ & 5 & \begin{tabular}{|l|l|}
0.36 \\
\end{tabular} & 0.44 & 0.18 & \begin{tabular}{|l|}
0.30 \\
\end{tabular} & \begin{tabular}{|l|l|}
0.42 \\
\end{tabular} & \begin{tabular}{|l|}
0.27 \\
\end{tabular} & \begin{tabular}{|l|}
0.18 \\
\end{tabular} & \begin{tabular}{|l|l|}
0.55 \\
\end{tabular} & \begin{tabular}{|l|l|}
0.53 \\
\end{tabular} & 0.40 & \begin{tabular}{|l|}
0.39 \\
\end{tabular} & \begin{tabular}{|l|l|}
0.21 \\
\end{tabular} & \begin{tabular}{|l|l|}
0.25 \\
\end{tabular} & \begin{tabular}{|l|}
0.28 \\
\end{tabular} & \begin{tabular}{|l|l}
0.43 & 0 \\
\end{tabular} & 0.54 & \begin{tabular}{|l|l|}
0.03 \\
\end{tabular} & \begin{tabular}{|l|c}
0.33 & 0 \\
\end{tabular} & \begin{tabular}{|l|l|}
0.13 \\
\end{tabular} & 0.21 & \begin{tabular}{|l|l}
0.23 \\
\end{tabular} & \begin{tabular}{|l|}
0.20 \\
\end{tabular} & \begin{tabular}{|l|} 
\\
\end{tabular} & \begin{tabular}{|l|}
1.00 \\
\end{tabular} & & & \\
\hline TCELL & $\mathrm{H} 26$ & \begin{tabular}{|l|l|}
0.42 \\
\end{tabular} & \begin{tabular}{|l|}
0.36 \\
\end{tabular} & \begin{tabular}{|l|}
0.27 \\
\end{tabular} & 0.26 & \begin{tabular}{|l|l|}
0.18 \\
\end{tabular} & \begin{tabular}{|l|l|}
0.24 \\
\end{tabular} & \begin{tabular}{|l|l|}
0.25 \\
\end{tabular} & \begin{tabular}{|l|l|}
0.14 \\
\end{tabular} & \begin{tabular}{|l|l|}
0.41 \\
\end{tabular} & \begin{tabular}{|l|}
0.37 \\
\end{tabular} & \begin{tabular}{|l|}
0.26 \\
\end{tabular} & \begin{tabular}{|l|}
0.40 \\
\end{tabular} & \begin{tabular}{|l|}
0.22 \\
\end{tabular} & \begin{tabular}{|l|}
0.23 \\
\end{tabular} & \begin{tabular}{|l|}
0.18 \\
\end{tabular} & \begin{tabular}{|l|l}
0.33 \\
\end{tabular} & $\begin{array}{l}0.46 \\
\end{array}$ & \begin{tabular}{|l|l|}
0.11 \\
\end{tabular} & \begin{tabular}{|l|c}
0.26 \\
\end{tabular} & \begin{tabular}{|l|l|}
0.09 \\
\end{tabular} & 0.20 & \begin{tabular}{|l|}
0.17 \\
\end{tabular} & \begin{tabular}{|l|l|}
0.13 \\
\end{tabular} & 0.26 & \begin{tabular}{|l|l|}
0.43 \\
\end{tabular} & \begin{tabular}{|l|l|} 
\\
\end{tabular} & & \\
\hline VAKBK & $\mathrm{H} 27$ & \begin{tabular}{|l|l}
0.80 \\
\end{tabular} & \begin{tabular}{|l|}
0.39 \\
\end{tabular} & \begin{tabular}{|l|}
0.55 \\
\end{tabular} & 0.16 & \begin{tabular}{|l|l|} 
\\
\end{tabular} & \begin{tabular}{|l|l|}
0.57 \\
\end{tabular} & \begin{tabular}{|l|}
0.35 \\
\end{tabular} & \begin{tabular}{|l|}
0.26 \\
\end{tabular} & \begin{tabular}{|l|l|}
0.83 \\
\end{tabular} & \begin{tabular}{|l|}
0.79 \\
\end{tabular} & \begin{tabular}{|l|l|}
0.49 \\
\end{tabular} & \begin{tabular}{|l|l|}
0.47 \\
\end{tabular} & \begin{tabular}{|l|}
0.31 \\
\end{tabular} & \begin{tabular}{|l|}
0.32 \\
\end{tabular} & \begin{tabular}{|l|}
0.36 \\
\end{tabular} & \begin{tabular}{|l|l}
0.43 & 0 \\
\end{tabular} & \begin{tabular}{|c|}
0.67 \\
\end{tabular} & \begin{tabular}{|l|}
0.02 \\
\end{tabular} & \begin{tabular}{|l|l}
0.36 & $C$ \\
\end{tabular} & \begin{tabular}{|l|}
0.16 \\
\end{tabular} & 0.23 & \begin{tabular}{|l|}
0.32 \\
\end{tabular} & \begin{tabular}{|l|l|}
0.28 \\
\end{tabular} & 0.50 & \begin{tabular}{|l|}
0.57 \\
\end{tabular} & \begin{tabular}{|l|l|}
0.40 \\
\end{tabular} & 1.00 & \\
\hline YKBNK & $\mathrm{H} 28$ & \begin{tabular}{|l|l|} 
\\
\end{tabular} & \begin{tabular}{|l|}
0.36 \\
\end{tabular} & 0.47 & 0.19 & \begin{tabular}{|l|l|}
0.28 \\
\end{tabular} & \begin{tabular}{|l|}
0.52 \\
\end{tabular} & \begin{tabular}{|l|}
0.32 \\
\end{tabular} & \begin{tabular}{|l|l|}
0.22 \\
\end{tabular} & \begin{tabular}{|l|l|}
0.78 \\
\end{tabular} & \begin{tabular}{|l|}
0.76 \\
\end{tabular} & 0.48 & \begin{tabular}{|l|}
0.49 \\
\end{tabular} & \begin{tabular}{|l|}
0.26 \\
\end{tabular} & \begin{tabular}{|l|}
0.30 \\
\end{tabular} & \begin{tabular}{|l|}
0.36 \\
\end{tabular} & \begin{tabular}{|l|l|}
0.39 & 0 \\
\end{tabular} & \begin{tabular}{l|l|}
0.64 \\
\end{tabular} & \begin{tabular}{|l|}
0.00 \\
\end{tabular} & \begin{tabular}{|l|c|}
0.30 \\
\end{tabular} & \begin{tabular}{|l|}
0.16 \\
\end{tabular} & 0.23 & \begin{tabular}{|l|}
0.37 \\
\end{tabular} & \begin{tabular}{|l|}
0.22 \\
\end{tabular} & \begin{tabular}{|l|} 
\\
\end{tabular} & \begin{tabular}{|l|}
0.52 \\
\end{tabular} & \begin{tabular}{|l|l|}
0.33 \\
\end{tabular} & \begin{tabular}{|l|l|} 
\\
\end{tabular} & 1.0 \\
\hline
\end{tabular}

